\title{
White Blood Cell Transcriptome Correlates With Renal Function in Acute Heart Failure
}

\author{
Sebastian Szmit, ${ }^{1}$ MD, Michal JAnK, ${ }^{2}$ DVM, Henryk Maciejewski, ${ }^{3} \mathrm{PhD}$, Pawel Balsam, ${ }^{1}$ MD, \\ Alicja Majewska, ${ }^{2} \mathrm{PhD}$, Magdalena LoJ, ${ }^{2} \mathrm{PhD}$, Marcin Grabowski, ${ }^{1} \mathrm{MD}$, \\ Krzysztof J. FiliPIAK, ${ }^{1}$ MD, Tomasz MotyL,${ }^{2}$ DVM, and Grzegorz OpOlsKI, ${ }^{1}$ MD
}

\begin{abstract}
SUMMARY
It is notoriously difficult to classify patients with acute heart failure (AHF) because of variations in clinical presentation, different etiologies, the impact of comorbidities, and variable prognoses. In this study, we used DNA whole-genome microarrays to classify 24 patients with AHF based on the transcriptome of their peripheral blood nuclear cells. The main purpose was to verify whether any transcriptomic sub-clusters had clinical correlations. We identified two distinct groups of transcriptomic profiles that correlated with normal $(1.125 \mathrm{mg} / \mathrm{dL})$ and increased $(1.783 \mathrm{mg} / \mathrm{dL}) \mathrm{mean}$ blood creatinine concentrations. These two subgroups of patients $(n=12)$ differed in the expression of more than 6000 genes and 108 signaling pathways. The most significant regulated signaling pathway was the aldosterone-regulated sodium reabsorption pathway and the most significant regulated genes included the angiotensin-converting enzyme gene. This suggests that kidney impairment in patients with AHF is related to dysregulation of the renin-angiotensin-aldosterone system. The interesting findings of our study were the significant differences in expression of genes belonging to the aldosterone-regulated signaling pathway: $\mathrm{Na}^{+} / \mathrm{K}^{+}$transporting ATPase and NEDD4L (neuronal precursor cell expressed developmentally down-regulated 4-like) between patients with and without renal dysfunction. Future studies of bloodcell transcriptomic profiles in patients with AHF will provide further insights into the molecular pathogenesis of this cardiorenal disorder. (Int Heart J 2012; 53: 117-124)
\end{abstract}

Key words: Peripheral blood nuclear cells, Gene expression, Whole-genome DNA microarray analysis, RNA hybridization, Reverse transcription polymerase chain reaction, Serum creatinine, Aldosterone-regulated sodium reabsorption pathway

$\mathrm{B}$ ecause acute heart failure (AHF) occurs suddenly and frequently leads to death, it would be of considerable medical value to have predictive or prognostic biomarkers of myocardial infarction (MI) or AHF. In recent years, many attempts have been made to identify markers of heart failure. Neutrophil gelatinase-associated lipocalin/lipocalin-2 is one such biomarker. The concentration of this glycoprotein is elevated in the serum of patients with AHF after a MI, and this concentration is correlated with the degree of clinical deterioration. ${ }^{1)}$ However, several other factors have also been described as biomarkers of MI, namely paraoxonase- 1 and paraoxonase- $2{ }^{2)}$ 5-lipoxygenase activating protein; ${ }^{3)}$ soluble intercellular adhesion molecule 1 , nuclear factor- $\kappa \mathrm{B}$ inhibitor kinase, patatin-like phospholipase domain-containing protein 3, RELA, and SH2B adaptor protein $3 ;^{4)}$ angiotensin-converting enzyme (ACE); ${ }^{5}$ vascular endothelial growth factor (VEGF); ${ }^{6,7)}$ and cytotoxic T-lymphocyte antigen $4{ }^{8)}$

Genetic factors have a significant role in the development of heart dysfunction. The sarcoglycan delta gene, for example, is implicated in heart failure in humans and hamsters, but not in dogs. ${ }^{9}$ Functional genomics and the use of DNA microarrays have allowed screening for a completely new class of markers, namely genomic markers. Genomic markers differ from genetic markers. Changes in genetic markers result from changes in gene structure (ie, gene mutations), whereas changes in genomic markers reflect altered expression of genes. A good example of such a marker is the chemokine CXCL16. ${ }^{10}$ Expression of the CXCL16 gene is increased in heart failure after MI, and plasma concentrations of the cytokine are increased in patients with chronic heart failure. In a previous study, ${ }^{11)}$ we showed that the CXCL16 gene was up-regulated in peripheral blood nuclear cells of patients with end-stage heart failure. This suggests that peripheral blood nuclear cells could yield potential new genomic markers of heart disease. RNA in peripheral blood can only originate from white blood cells, which prompted us to hypothesize that such markers could reflect changes in the regulation of chemokines or other signaling molecules. Irrespective of the material investigated, technological advances now allow the simultaneous analysis of thousands of genes and the identification of many up- or downregulated clustered genes. A recent review identified several potential genomic markers of heart failure, including APOB, APOE, ACE, PAI-1, MTHFR, CETP, eNOS, prothrombin, GWAS, CELSR2, PSRC1, SORT1, MRPS6, KCNE2, MIA3,

From the ${ }^{1}$ First Department of Cardiology, Medical University of Warsaw, ${ }^{2}$ Department of Physiological Sciences, Faculty of Veterinary Medicine, Warsaw University of Life Sciences, Warsaw, and ${ }^{3}$ Institute of Computer Engineering, Control and Robotics (I-6), Wroclaw University of Technology, Wroclaw, Poland.

The manuscript reports the results of research funded by a grant from the Polish Cardiac Society.

Address for correspondence: Sebastian Szmit MD, First Department of Cardiology, Medical University of Warsaw, Banacha-Street 1a, 02-097 Warsaw, Poland.

Received for publication October 18, 2011

Revised and accepted February 2, 2012. 
PHACTR1, LDLR, CXCL12, PCSK9, WDR12, and MRAS. ${ }^{12)}$ Characterization of the relationships between these genomic markers and the complete signaling pathways in which specific genes are involved might therefore provide insights into the molecular pathogenesis of heart disease.

The prognosis for patients with AHF is poor in both the short and the long term. ${ }^{13,14)}$ Clinically, AHF is characterized by lung congestion, ${ }^{15)}$ and sometimes pulmonary edema. ${ }^{16)}$ Many patients have additional symptoms, such as reduced cardiac output and impaired peripheral perfusion. Severe AHF can lead to multiple organ failure and death, and therefore requires urgent medical intervention. AHF is usually a complication of an acute coronary syndrome. However, AHF sometimes develops in patients with chronic heart disease, despite appropriate treatment. This typically results from the progression of heart disease and concomitant noncardiovascular diseases. Unfavorable prognostic factors for AHF are similar to those in chronic heart failure. ${ }^{17)}$ Clinically it is difficult to classify patients with AHF. For example, the clinical presentation is often different, and the etiology of the condition can vary. Comorbidities can also have an impact on the clinical picture, and the lack of a distinct prognosis can complicate the process of classification. Characterization of relevant molecular factors in patients with AHF would thus be useful.

In this study we attempted to classify patients with $\mathrm{AHF}$ based on the transcriptome of their peripheral blood nuclear cells and to verify whether any transcriptomic sub-clusters had clinical correlations. Using this novel approach, we looked for transcriptomic profiles of many differentially regulated genes, rather than for individual genes. Establishing a transcriptomic classification of patients with AHF would have prognostic value and could also provide information about disease pathogenesis.

\section{Methods}

Patients: The study included 24 patients with a history of heart disease who were admitted to our Cardiology Department with a diagnosis of AHF. Patients with de novo AHF, MI with ST elevation as a cause of AHF, prehospital cardiac arrest, pulmonary embolism or stroke, cancer or severe lung disease, or a previous history of chronic kidney were excluded. All patients were diagnosed and treated according to the current clinical management guidelines. ${ }^{18)}$

Chest X-rays were performed on all patients to assess the degree of lung congestion. The following laboratory tests were performed: complete blood count, serum sodium, potassium, urea, creatinine, albumin, liver enzymes, prothrombin time/international normalized ratio (PT/INR) and troponin. Doppler echocardiography was performed to evaluate segmental and global systolic function of the left and right ventricles, diastolic ventricular function, and morphology and function of the heart valves.

The study was approved by the local Ethics Committee of the Medical University of Warsaw and all participants gave written informed consent.

RNA isolation, validation, labeling, and hybridization: Duplicate blood samples were obtained from the antecubital vein of each patient and collected in PAXGene tubes (Qiagen, USA). Total RNA from peripheral blood nuclear cells was isolated using a PAXgene Blood RNA kit (Qiagen, USA). Isolated RNA samples were dissolved in RNAase-free water, and the RNA quantity was measured spectrophotometrically using a NanoDrop (NanoDrop Technologies, USA). Samples with an adequate amount of RNA were treated with DNAase I to eliminate DNA contamination and then purified using an RNeasy MiniElute Cleanup Kit (Qiagen, Germany). The analysis of final RNA quality and integrity was performed with a BioAnalyzer (Agilent, USA).

The analysis of gene-expression profile was performed using SurePrint G3 Hmn GE 8x60K (Agilent Technologies, USA). Each slide contained 8 microarrays representing about 60,000 predicted human mRNAs. Experiments were performed using a common reference design, where the common reference was a pool of equal amounts of RNA from all the patients. On each two-color microarray, we hybridized $100 \mathrm{ng}$ of total RNA isolated from individual patients, and $100 \mathrm{ng}$ of total RNA from the pool. Sample labeling, amplification, and microarray hybridization were performed with the appropriate kits supplied by the manufacturer of the microarrays (Agilent Technologies, USA), and according to the manufacturer's protocols. Acquisition and analysis of hybridization intensities were performed using an Agilent DNA microarray scanner.

Statistical analysis: The raw probe data were loss normalised, and microarray probes not related to genes were discarded. Probes replicated in the array were then averaged. The log-ratio of the sample to the reference signal was calculated and the data were then median-centered. Clustering was performed for rows and columns of the gene expression matrix, where rows correspond to genes and columns correspond to samples. The measure of distance between (row or column) vectors was defined as 1 minus Spearman's correlation coefficient between the vectors. A hierarchical clustering algorithm was used with Ward's minimum variance linkage function. The groups identified in the unsupervised classification were correlated with clinical data from the patients. When correlations were found, the groups of patients were also compared using Student's $t$ test for unequal variances and the nonparametric Wilcoxon rank test.

The groups of patients identified by correlation of unsupervised classification results and clinical data were compared for differentially expressed genes. The differential expression analysis was performed using linear methods for microarrays

Table I. Primers Used For Real-Time RT-PCR in This Study

\begin{tabular}{lll}
\hline Primer & \multicolumn{1}{c}{ L sequence } & \multicolumn{1}{c}{ R sequence } \\
\hline ATP1B3 & CACCATGACGAAGAACGAGA & CTGGGCTAGGAATCTGGTCA \\
NEDD4L & TTGAGGTCATGCAGTGTCA & GCAAGCTGCATGATAGGTC \\
GAPDH & GAGTCAACGGATTTGGTCGT & TTGATTTTGGAGGGATCTCG \\
\hline
\end{tabular}


Table II. Characteristics of Patients With AHF

\begin{tabular}{|c|c|c|c|}
\hline Characteristic & All patients $(n=24)$ & Group $1(n=12)$ & Group $2(n=12)$ \\
\hline Creatinine $(\mathrm{mg} / \mathrm{dL})$, mean \pm SEM & $1.45 \pm 0.73$ & $1.783 \pm 0.886^{*}$ & $1.125 \pm 0.308^{*}$ \\
\hline Gender (male/female) & $19 / 5$ & $11 / 1$ & $8 / 4$ \\
\hline Age (years), mean \pm SEM & $68.6 \pm 12.3$ & $66.3 \pm 10.7$ & $70.9 \pm 13.8$ \\
\hline \multirow[t]{2}{*}{$\begin{array}{l}\text { Type of myocardial infarction in } \\
\text { anamnesis }(n)\end{array}$} & $\begin{array}{l}\text { apical }=6 \\
\text { anterior }=6\end{array}$ & $\begin{array}{c}\text { apical }=1 \\
\text { anterior }=3\end{array}$ & $\begin{array}{c}\text { apical }=5 \\
\text { anterior }=3\end{array}$ \\
\hline & $\begin{array}{c}\text { other localization }=6 \\
\text { none }=6\end{array}$ & $\begin{array}{c}\text { other localization }=5 \\
\text { none }=3\end{array}$ & $\begin{array}{c}\text { other localization }=1 \\
\text { none }=3\end{array}$ \\
\hline \multirow[t]{7}{*}{ Cause of AHF $(n)$} & ischemia $=6$ & ischemia $=4$ & ischemia $=2$ \\
\hline & overload $=5$ & overload $=3$ & overload $=2$ \\
\hline & valve dysfunction $=3$ & valve dysfunction $=0$ & valve dysfunction $=3$ \\
\hline & infection $=3$ & infection $=2$ & infection $=1$ \\
\hline & hypertension $=3$ & hypertension $=0$ & hypertension $=3$ \\
\hline & myocarditis $=2$ & myocarditis = 1 & myocarditis = 1 \\
\hline & arrhythmia $=2$ & arrhythmia $=2$ & arrhythmia $=0$ \\
\hline Pulmonary edema $(n)$ & 9 & 3 & 6 \\
\hline Need for inotropic therapy $(n)$ & 7 & 3 & 4 \\
\hline Elevated troponins $(n)$ & 11 & 6 & 5 \\
\hline NTproBNP $[\mathrm{pg} / \mathrm{mL}]$, mean \pm SEM & $7523.1 \pm 4825.1$ & $7974.5 \pm 5891.2$ & $7071.7 \pm 4003.2$ \\
\hline Hemoglobin $(\mathrm{g} / \mathrm{dL})$, mean \pm SEM & $13.2 \pm 1.9$ & $12.8 \pm 1.9$ & $13.5 \pm 1.9$ \\
\hline $\mathrm{WBC}\left(\times 10^{9} / \mathrm{L}\right)$, mean $\pm \mathrm{SEM}$ & $10.8 \pm 4.8$ & $11.0 \pm 5.6$ & $10.7 \pm 4.1$ \\
\hline $\begin{array}{l}\text { Left ventricular ejection fraction } \\
(\%) \text {, mean } \pm \text { SEM }\end{array}$ & $37.8 \pm 14.6$ & $28.1 \pm 16.7$ & $38.0 \pm 19.9$ \\
\hline \multirow[t]{5}{*}{ Mitral regurgitation } & none $=4$ & none $=3$ & none $=1$ \\
\hline & one $=9$ & one $=2$ & one $=7$ \\
\hline & two $=4$ & two $=2$ & two $=2$ \\
\hline & three $=5$ & three $=4$ & three $=1$ \\
\hline & four $=2$ & four $=1$ & four $=1$ \\
\hline $\begin{array}{l}\text { Hospitalization period (days), } \\
\text { mean } \pm \text { SEM }\end{array}$ & $15.3 \pm 12.7$ & $16.4 \pm 15.5$ & $14.2 \pm 9.7$ \\
\hline \multirow[t]{3}{*}{ Follow-up } & death $=3$ & death $=2$ & death $=1$ \\
\hline & improvement to NYHA III = 9 & improvement to NYHA III = 5 & improvement to NYHA III = 4 \\
\hline & improvement to NYHA I/II = 12 & improvement to NYHA I/II $=5$ & improvement to NYHA I/II $=7$ \\
\hline \multirow[t]{6}{*}{ Treatment before hospitalization } & $\begin{array}{l}\text { angiotensin-converting enzyme } \\
\text { inhibitors }=18\end{array}$ & $\begin{array}{c}\text { angiotensin-converting enzyme } \\
\text { inhibitors }=9\end{array}$ & $\begin{array}{c}\text { angiotensin-converting enzyme } \\
\text { inhibitors }=9\end{array}$ \\
\hline & aldosterone antagonists $=7$ & aldosterone antagonists $=3$ & aldosterone antagonists $=4$ \\
\hline & beta-blockers $=17$ & beta-blockers $=9$ & beta-blockers $=8$ \\
\hline & antiplatelet therapy $=18$ & antiplatelet therapy $=9$ & antiplatelet therapy $=9$ \\
\hline & statin $=20$ & statin $=9$ & statin $=11$ \\
\hline & diuretics $=10$ & diuretics $=5$ & diuretics = 5 \\
\hline
\end{tabular}

There were no significant differences in clinical data between patients with normal (group 2) and increased (group 1) mean blood creatinine concentrations. AHF indicates acute heart failure; CL, confidence limit; NYHA, New York Heart Association; SEM, standard error of the mean; and WBC, white blood cells. ${ }^{*} P<0.05$

(Bioconductor limma package). Associations of gene expression in Kyoto Encyclopedia of Genes and Genomes (KEGG) pathways were analyzed in the groups of samples discovered by clustering. The global test method ${ }^{19)}$ was used to identify pathways with most differential expression of genes between groups 1 and 2 . The pathway analyses were performed with the limma ${ }^{20)}$ and global test R/Bioconductor packages, and the statistical analysis was performed using the SAS statistical package.

Real-time RT-PCR: Expressions of NEDD4L (the gene for the enzyme E3 ubiquitin-protein ligase neural precursor cell expressed, developmentally down-regulated 4-like) and ATP genes were checked by real-time RT-PCR using ATP1B3, NEDD4L, and GAPDH primers (Table I). All analyses were performed on all individual samples of total RNA using a LightCycler FastStart DNA Master SYBR Green I kit (Roche Diagnostics $\mathrm{GmBH}$, Germany) as follows: $\mathrm{Mg}^{2+}$ was added to a final concentration of $3 \mathrm{mM}$; preincubation at $95^{\circ} \mathrm{C}$ for 10 minutes; amplification (40 cycles) including denaturation at $95^{\circ} \mathrm{C}$ for 10 seconds, annealing at $58^{\circ} \mathrm{C}\left(60^{\circ} \mathrm{C}\right.$ for $\left.\mathrm{GAPDH}\right)$ for 10 seconds, extension at $72^{\circ} \mathrm{C}$ for 10 seconds ( 12 seconds for GAPDH); melting curve including denaturation at $95^{\circ} \mathrm{C}$ for 0 seconds, annealing at $58^{\circ} \mathrm{C}\left(60^{\circ} \mathrm{C}\right.$ for GAPDH) for $15 \mathrm{sec}-$ onds, continuous melting at $95^{\circ} \mathrm{C}$ for 0 seconds (slope $=0.1^{\circ} \mathrm{C}$ / s); cooling at $40^{\circ} \mathrm{C}$ for 30 seconds. Results were calculated using the $2^{-\Delta \Lambda \mathrm{C}} \mathrm{T}$ method. ${ }^{21)}$ The average expressions (with standard deviations) in both groups were compared using Student's unpaired $t$-test in GraphPad Prism software (GraphPad, USA).

\section{RESULTS}

Patient characteristics: Patient characteristics are shown in Table II.

Unsupervised classification: The results of the unsupervised classification are shown in Figure 1. Cluster analysis revealed 


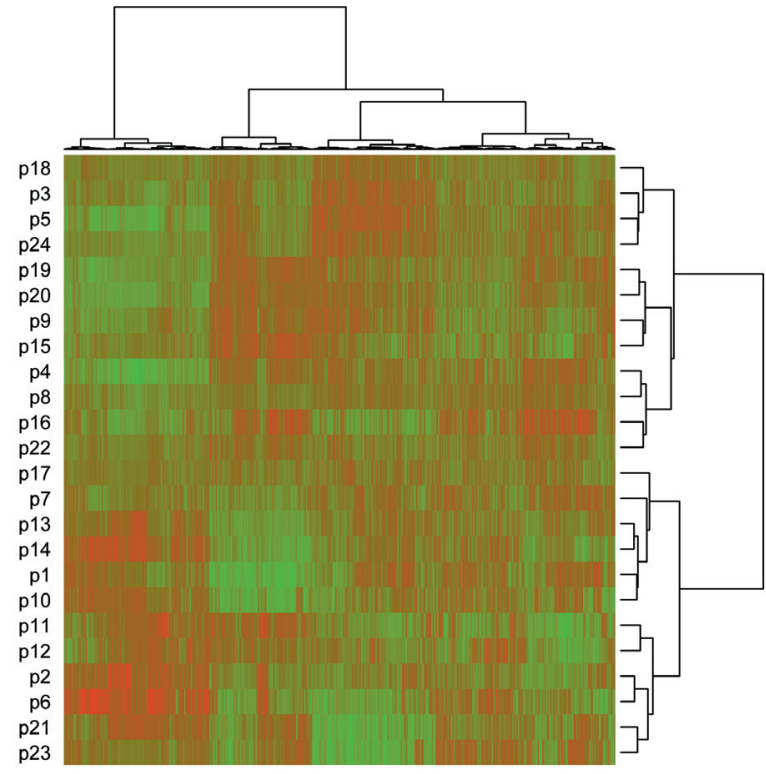

Figure 1. Results of hierarchical clustering of gene expression data with rows corresponding to genes and columns to samples (patients).

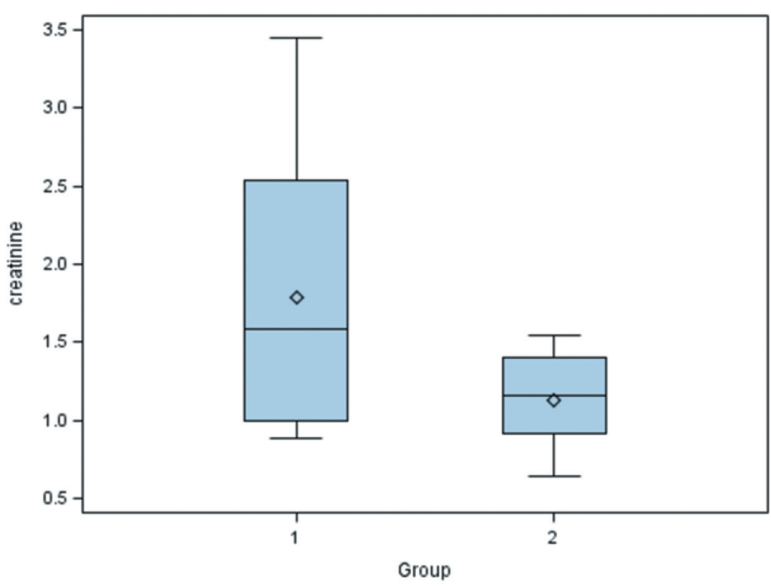

Figure 2. Distribution of blood creatinine concentrations in the two groups of patients identified by unsupervised classification.

two groups of patients with distinct gene expression profiles: patient identity codes p17, p7, p13, p14, p1, p10, p11, p12, p2, $\mathrm{p} 6, \mathrm{p} 21, \mathrm{p} 23$ (group 1) and patient identity codes p18, p3, p5, p24, p19, p20, p9, p15, p4, p8, p16, p22 (group 2).

Correlation between unsupervised classification and clinical data: The groups identified by cluster analysis were correlated with clinical data for symptoms (pulmonary edema and low cardiac output), sex, age, history of heart disease, coexisting diseases, echocardiographic findings, etiology of AHF, the results of standard laboratory tests, and patient follow-up. The groups with different transcriptomic profiles also differed significantly in terms of blood creatinine concentration. The distribution of creatinine concentrations is shown in Figure 2. The groups were also compared using Student's $t$-test for unequal

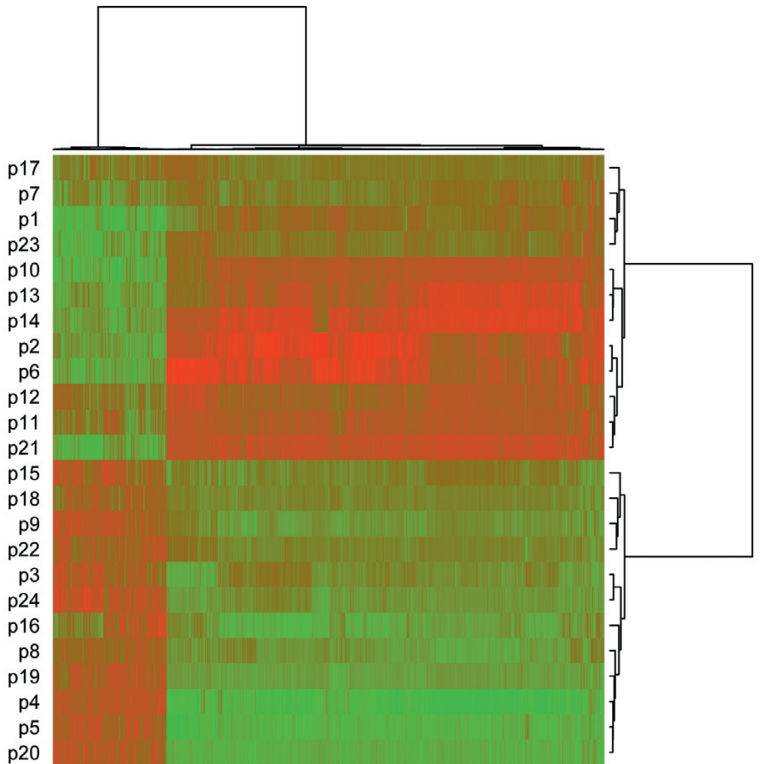

Figure 3. Results of reclustering of the expression data (Ward method) for the 2000 genes expressed most differently between the two groups of patients identified by unsupervised classification.

variances and Wilcoxon's nonparametric rank test, which gave $P=0.029$ and $P=0.035$, respectively. There were no other correlations between clinical and transcriptomic data. Moreover, there were no significant differences in clinical data between patients with normal (group 2) and increased (group 1) mean blood creatinine concentrations (Table II).

Differentially expressed genes identified by unsupervised classification: Analyses revealed about 6000 differentially expressed genes between the groups (false-discovery rate-adjusted $P$ value $<0.01$ ) (data not shown). The data were reclustered in the space of the 2000 most differentially expressed genes, as shown in Figure 3. The results included 108 pathways which showed significant differential expression between groups (Holm adjusted $P<0.05$ for the test of no association of expression in pathways with the group identity) (data not shown). The most significantly regulated signaling pathway was the aldosterone-regulated sodium reabsorption pathway (Holm-adjusted $P=0.00000683$ ). This pathway consists of 39 different genes, 15 of which were differentially regulated (Table III).

Real-time PCR difference in NEDD4L and ATP1B3 genes in groups of patients identified by unsupervised classification: The expressions of NEDD4L and ATP1B3 genes measured using real-time PCR were in accordance with the expressions measured on microarrays (Table IV). The average expression of NEDD4L in group 2 was 1.6 times higher than that in group 1 (3.92 times higher on microarrays), whereas ATP1B3 expression in group 2 was 1.811 times lower than in group 1 ( 3.25 times lower on microarrays). For both genes the differences were statistically significant $(P<0.05)$. 
Table III. Differentially Expressed Genes From the Aldosterone-Regulated Sodium Reabsorption Pathway in Patients With Normal Mean Blood Creatinine Concentration (1.175 mg/dL) Compared With Patients With Increased Mean Blood Creatinine Concentrations (1.783 mg/dL)

\begin{tabular}{|c|c|c|c|c|c|c|}
\hline No & $\begin{array}{l}\text { Gene } \\
\text { Symbol }\end{array}$ & Description & $\log \mathrm{FC}$ & $\mathrm{T}$ & $P$ & $\begin{array}{c}\text { Adjusted } \\
P\end{array}$ \\
\hline 1 & MAPK3 & $\begin{array}{l}\text { Homo sapiens mitogen-activated protein kinase } 3 \text { (MAPK3), transcript variant 1, mRNA } \\
\text { [NM_002746] }\end{array}$ & 0.57 & 5.51 & 0.0000098200 & 0.0003230000 \\
\hline 2 & PIK3CD & $\begin{array}{l}\text { Homo sapiens phosphoinositide-3-kinase, catalytic, delta polypeptide (PIK3CD), mRNA } \\
\text { [NM_005026] }\end{array}$ & 0.66 & 4.89 & 0.0000488000 & 0.0007190000 \\
\hline 3 & FXYD4 & $\begin{array}{l}\text { Homo sapiens FXYD domain containing ion transport regulator } 4 \text { (FXYD4), mRNA } \\
\text { [NM_173160] }\end{array}$ & 0.87 & 4.82 & 0.0000585000 & 0.0008010000 \\
\hline 4 & PRKCA & Homo sapiens protein kinase C, alpha (PRKCA), mRNA [NM_002737] & -0.81 & -4.42 & 0.0001640000 & 0.0015900000 \\
\hline 5 & ATP1A3 & $\begin{array}{l}\text { Homo sapiens ATPase, } \mathrm{Na}+/ \mathrm{K}+\text { transporting, alpha } 3 \text { polypeptide (ATP1A3), mRNA } \\
\text { [NM_152296] }\end{array}$ & 0.58 & 4.23 & 0.0002720000 & 0.0022600000 \\
\hline 6 & PDPK1 & $\begin{array}{l}\text { Homo sapiens 3-phosphoinositide dependent protein kinase-1 (PDPK1), transcript vari- } \\
\text { ant 1, mRNA [NM_002613] }\end{array}$ & -0.49 & -4.13 & 0.0003460000 & 0.0026600000 \\
\hline 7 & PIK3R1 & $\begin{array}{l}\text { Homo sapiens phosphoinositide-3-kinase, regulatory subunit } 1 \text { (alpha) (PIK3R1), tran- } \\
\text { script variant 1, mRNA [NM_181523] }\end{array}$ & -0.76 & -4.1 & 0.0003820000 & 0.0028400000 \\
\hline 8 & NEDD4L & $\begin{array}{l}\text { Homo sapiens neural precursor cell expressed, developmentally down-regulated 4-like } \\
\text { (NEDD4L), transcript variant j, mRNA [NM_001144967] }\end{array}$ & 0.97 & 3.92 & 0.0006020000 & 0.0039100000 \\
\hline 9 & $\mathrm{NR} 3 \mathrm{C} 2$ & $\begin{array}{l}\text { Homo sapiens nuclear receptor subfamily } 3 \text {, group C, member } 2 \text { (NR3C2), transcript var- } \\
\text { iant 1, mRNA [NM_000901] }\end{array}$ & -1.69 & -3.64 & 0.0012400000 & 0.0066200000 \\
\hline 10 & ATP1B2 & $\begin{array}{l}\text { Homo sapiens ATPase, } \mathrm{Na}+\mathrm{K}+\text { transporting, beta } 2 \text { polypeptide (ATP1B2), mRNA } \\
\text { [NM_001678] }\end{array}$ & 0.79 & 3.6 & 0.0013400000 & 0.0070200000 \\
\hline 11 & KRAS & $\begin{array}{l}\text { Homo sapiens v-Ki-ras2 Kirsten rat sarcoma viral oncogene homolog (KRAS), transcript } \\
\text { variant a, mRNA [NM_033360] }\end{array}$ & -0.84 & -3.44 & 0.0020100000 & 0.0093900000 \\
\hline 12 & ATP1B3 & $\begin{array}{l}\text { Homo sapiens ATPase, } \mathrm{Na}+\mathrm{K}+\text { transporting, beta } 3 \text { polypeptide (ATP1B3), mRNA } \\
\text { [NM_001679] }\end{array}$ & -0.59 & -3.25 & 0.0033000000 & 0.0135000000 \\
\hline 13 & ATP1B1 & $\begin{array}{l}\text { Homo sapiens ATPase, } \mathrm{Na}+\mathrm{K}+\text { transporting, beta } 1 \text { polypeptide (ATP1B1), transcript } \\
\text { variant } 1 \text {, mRNA [NM_001677] }\end{array}$ & -0.79 & -3.24 & 0.0033600000 & 0.0137000000 \\
\hline 14 & IGF1 & $\begin{array}{l}\text { Homo sapiens insulin-like growth factor } 1 \text { (somatomedin C) (IGF1), transcript variant } 4 \text {, } \\
\text { mRNA [NM_000618] }\end{array}$ & 0.71 & 3.18 & 0.0038900000 & 0.0153000000 \\
\hline 15 & PIK3CD & $\begin{array}{l}\text { Homo sapiens phosphoinositide-3-kinase, catalytic, delta polypeptide (PIK3CD), mRNA } \\
\text { [NM_005026] }\end{array}$ & -0.32 & -2.59 & 0.0156000000 & 0.0427000000 \\
\hline 16 & SGK1 & $\begin{array}{l}\text { Homo sapiens serum/glucocorticoid regulated kinase } 1 \text { (SGK1), transcript variant 1, } \\
\text { mRNA [NM_005627] }\end{array}$ & -0.89 & -2.45 & 0.0215000000 & 0.0545000000 \\
\hline 17 & ATP1A1 & $\begin{array}{l}\text { Homo sapiens ATPase, Na+/K+ transporting, alpha } 1 \text { polypeptide (ATP1A1), transcript } \\
\text { variant } 1 \text {, mRNA [NM_000701] }\end{array}$ & -0.25 & -2.12 & 0.0437000000 & 0.0933000000 \\
\hline 18 & PIK3R2 & $\begin{array}{l}\text { Homo sapiens phosphoinositide-3-kinase, regulatory subunit } 2 \text { (beta) (PIK3R2), mRNA } \\
\text { [NM_005027] }\end{array}$ & 0.43 & 2.09 & 0.0467000000 & 0.0982000000 \\
\hline
\end{tabular}

Gene descriptions include the USA National Centre for Biotechnology Information Reference Sequence accession number. LogFC is the logarithmically transformed fold change in gene expression. T is the fold change calculated by Student's $t$ test; the $P$ was calculated using the $t$ test; and Adjusted $P$ allows for a false discovery rate $<0.01$.

Table IV. Real-Time RT-PCR Expression of NEDD4L and ATP1B3 Genes in the Two Groups of Patients Identified by Unsupervised Classification

\begin{tabular}{lccc}
\hline Gene & Group 1 & Group 2 & $P$ \\
\hline ATP1B3 (mean \pm SEM) & $1.245 \pm 0.2218$ & $0.6844 \pm 0.1505$ & 0.0475 \\
NEDD4L (mean \pm SEM) & $0.4925 \pm 0.05817$ & $0.7936 \pm 0.08905$ & 0.0013 \\
\hline
\end{tabular}

\section{Discussion}

Our results suggest that it is possible to classify cardiac patients based on the transcriptomic profile of their peripheral blood nuclear cells, and that this classification correlates with their renal function. While we acknowledge that patients with AHF and kidney dysfunction can easily be identified solely by measuring their blood creatinine concentration, we believe that our study is the first to show that an elevated blood creatinine concentration is correlated with the gene expression pattern in peripheral blood nuclear cells. The unsupervised classification of the patient transcriptomic profiles using two different methods gave similar results. The transcriptomic analyses of patients with AHF yielded two distinct profiles. Differentially expressed genes in these two subgroups revealed more than 6000 genes, with a false-discovery rate less than 0.01 . These two subgroups of patients with different transcriptomic profiles differed significantly in mean blood creatinine concentration, which suggests one group with normal renal function and a second group with impaired renal function. Since all patients had AHF, we conclude that transcriptomic profiling of peripheral blood nuclear cells by DNA microarray allowed the identification of renal injury in these cardiac patients. There were no correlations with any other clinical parameters that we assessed, eg, the presence of pulmonary edema, troponin concentrations, or echocardiographic findings.

There are several diseases that coexist with heart failure, including renal failure, anemia, chronic obstructive pulmonary disease, diabetes, depression, and breathing disorders during sleep. Increasingly, a spectrum of cardiorenal syndromes, ${ }^{22-24}$ 
together with the inter-relatedness and bidirectional interaction of the renal and cardiovascular systems, has been recognized. A meta-analysis of heart-failure studies showed that every second patient with heart failure has concomitant renal dysfunction. ${ }^{25)}$ In this patient group, the occurrence of renal dysfunction is associated with a $50 \%$ increased risk of death. An analysis of 5 clinical trials demonstrates that the risk of death is more than two-fold higher (HR 2.31, 95\% CI 2.18-2.44, $P<$ 0.001 ) in patients with moderate to severe renal failure. If kidney function is defined by serum creatinine concentration (as in this study), the risk of death increases significantly with every $1 \mathrm{mg} / \mathrm{dL}$ increase in creatinine concentration. ${ }^{26-28)}$

These results illustrate that there are molecular differences within AHF patients that determine renal function, irrespective of their history of heart disease, other coexisting diseases, the etiology of the AHF, and echocardiographic and standard laboratory test results. Surprisingly, symptoms of pulmonary edema and low cardiac output, troponin concentration, the incidence of anemia, and markers of inflammation or liver function did not correlate with the blood-cell transcriptomic profile.

Our findings suggest that a subgroup of patients with $\mathrm{AHF}$ and renal dysfunction represents a separate disease subtype, for which alternative therapeutic procedures may be appropriate. Renal dysfunction correlates with an abnormal response of the renin-angiotensin-aldosterone (RAA) system. Drugs that act on this system (eg, ACE inhibitors and aldosterone antagonists) reduce the risk of death in patients with heart failure. However, the evidence for this comes from studies mainly in patients with normal renal function. Data about whether these drugs improve the prognosis of patients with renal dysfunction is less reliable. Our findings indicate that the results for RAA-targeted therapy should not be extrapolated to patients with elevated serum creatinine, because there are significant molecular differences in this group. In addition, drugs that interfere with the RAA system worsen renal function, leading to further increases in creatinine concentrations. Although Ezekowitz, et $a l^{29)}$ showed that patients with renal dysfunction may benefit from ACE-inhibitor therapy, patients in this group rarely receive optimal therapy consistent with current management guidelines. Interestingly, ACE is also considered to be a potential genetic marker of both $\mathrm{MI}^{5)}$ and kidney failure. $^{30,31)}$ In our study, the expression of the ACE gene was differentially regulated in patients with and without kidney dysfunction, which suggests that in some patients, but not others, the development of AHF is associated with changes in ACE gene expression. Some patients may have low expression of ACE even before the development of AHF, which could explain why treatment with ACE-inhibitors is unsuccessful in these patients.

The differentially expressed genes identified in our study represented 108 different signaling pathways. Of these, the most significant differentially regulated pathway was the aldosterone-regulated sodium reabsorption pathway (Holm-adjusted $P<0.00000683$ ). This pathway consists of 39 different genes of which we identified 15 regulated genes (adjusted $P<$ $0.05)$. Notably, net changes in the expression of individual genes were not remarkable, but over the pathway as a whole the altered level of expression was highly significant. This suggests that significant regulation of a whole signaling pathway can occur in the absence of major changes in the expression of individual genes. Consistent with this, we assume that the changed aldosterone-regulated sodium reabsorption pathway is a consequence of altered expression of the ACE gene because regulation of ACE expression would lead to changes in aldosterone concentrations.

In patients with heart failure, aldosterone is secreted not only by the adrenal glands, but also by cardiomyocytes and vascular myocytes. ${ }^{32,33)}$ Aldosterone stimulates collagen production, leading to adverse structural remodeling of the heart and blood vessels, ${ }^{34)}$ and activates the sympathetic nervous system. ${ }^{35)}$ Clinically, the effects of aldosterone overactivity are fluid overload, cardiac dysfunction and ventricular arrhythmias, ${ }^{36)}$ resulting in increased mortality. ${ }^{37)}$ Randomized clinical trials have demonstrated that the use of the aldosterone antagonists spironolactone and eplerenone prolongs the lives of patients with heart failure. ${ }^{38-40)}$ Our study indicated that the aldosterone-dependent signaling pathway is most significantly regulated in patients with AHF and increased blood creatinine levels, which further suggests that drugs that act on this pathway could be of clinical importance in patients with heart failure.

The changes in the expression of genes belonging to the aldosterone-regulated signaling pathway were confirmed by real-time PCR, which revealed increased expression of $\mathrm{Na}^{+} / \mathrm{K}^{+}$ transporting ATPase (represented within the pathway by 7 genes coding different ATPase subunits) and NEDD4L. We know that reduced $\mathrm{Na}^{+} / \mathrm{K}^{+}$ATPase activity has been demonstrated in patients with heart failure and dilated cardiomyopathy. ${ }^{41,42)}$ This reduced activity correlates with a decrease in LVEF $^{43)}$ and the risk of cardiac arrhythmias. ${ }^{44)}$ Significant changes in the activity of the sodium-potassium pump have also been observed in patients with myocardial ischaemia. ${ }^{45,46)}$ NEDD4L is a regulator of the amiloride-sensitive epithelial sodium channel, ${ }^{47)}$ and plays an important role in cardiovascular disease, especially hypertension. Variants of the NEDD4L gene may also contribute to individual variations in blood pressure $^{48)}$ and to the outcome of treatment. For example, Svensson-Färbom, et $a l^{49)}$ showed that polymorphism in the NEDD4L gene (rs4149601) influences the efficacy of $\beta$-blockerand/or diuretic-based antihypertensive treatment but not diltiazem-based antihypertensive treatment. If the changes in the regulation of these two signaling components would be correlated with treatment efficacy in patients with heart failure (which requires further studies), they might become a genetic and genomic marker of kidney failure in AHF patients.

The search for potential genomic biomarkers of heart or kidney failure within peripheral blood nuclear cells seems reasonable given the increasing use of blood cells in cardiovascular research. According to Horwitz, et $a l^{50)}$ expression profiles of blood cells may be a more sensitive screening test for cardiac allograft rejection than endomyocardial biopsy. Peripheral blood gene expression is also correlated with the extent of coronary heart disease ${ }^{51)}$ and chronic heart failure, ${ }^{52)}$ and could be used to differentiate patients with ischemic end-stage heart failure from patients with asymptomatic heart dysfunction. ${ }^{11)}$ Recently, Devaux, et $a l^{53}$ identified a set of 3 potential biomarkers (VEGFB, THBS1 and PGF) of left ventricular dysfunction in blood cells from patients after MI. One of these genes, THBS1, was also regulated in our study and was found to differ significantly in patients with kidney dysfunction. Peripheral blood genomic biomarkers also have potential in discriminating acute rejection from nonrejection in cardiac transplant re- 
cipients. ${ }^{54)}$ Investigation of the blood cell transcriptomic profiles in patients with cardiovascular disorder thus appears to be a promising field of research.

In summary, we have shown for the first time that the transcriptomic profile of peripheral blood nuclear cells in patients with AHF is correlated with the concentration of blood creatinine. Among patients with AHF, we were able to identify distinct and separate transcriptomic profiles for patients with kidney failure (mean blood creatinine concentration $=1.783$ $\mathrm{mg} / \mathrm{dL}$ ) and those with healthy kidneys (mean creatinine concentration $=1.175 \mathrm{mg} / \mathrm{dL}$ ). The regulated signaling pathway that differed most significantly between these two patient groups was the aldosterone-regulated sodium reabsorption pathway. This differential expression, together with the regulation of ACE gene expression, points to a critical role for kidney function (and the RAA system) in patients with heart failure. Larger, long-term studies are needed to assess whether the potential associations between these correlate with long-term survival and treatment effectiveness in these patients. Such studies may also help identify the molecular processes involved in AHF in humans.

\section{REFERENCES}

1. Yndestad A, Landrø L, Ueland T, et al. Increased systemic and myocardial expression of neutrophil gelatinase-associated lipocalin in clinical and experimental heart failure. Eur Heart J 2009; 30: 1229-36.

2. Janka Z, Juhász A, Rimanóczy AA, Boda K, Márki-Zay J, Kálmán J. Codon 311 (Cys --> Ser) polymorphism of paraoxonase-2 gene is associated with apolipoprotein E4 allele in both Alzheimer's and vascular dementias. Mol Psychiatry 2002; 7: 110-2.

3. Helgadottir A, Manolescu A, Thorleifsson A, et al. The gene encoding 5-lipoxygenase activating protein confers risk of myocardial infarction and stroke. Nat Genet 2004; 36: 233-9.

4. Paré G, Ridker PM, Rose L, et al. Genome-wide association analysis of soluble ICAM-1 concentration reveals novel associations at the NFKBIK, PNPLA3, RELA, and SH2B3 loci. PLoS Genet 2011; 7: e1001374

5. Parenica J, Goldbergova MP, Kala P, et al. ACE gene insertion/deletion polymorphism has a mild influence on the acute development of left ventricular dysfunction in patients with ST elevation myocardial infarction treated with primary PCI. BMC Cardiovasc Disord 2010; 10: 60.

6. Douvaras P, Antonatos DG, Kekou K, et al. Association of VEGF gene polymorphisms with the development of heart failure in patients after myocardial infarction. Cardiology 2009; 114: 11-8.

7. Petrovic D. The role of vascular endothelial growth factor gene as the genetic marker of atherothrombotic disorders and in the gene therapy of coronary artery disease. Cardiovasc Hematol Agents Med Chem 2010; 8: 47-54.

8. Yip HK, Wang PW, Chang LT, et al. Cytotoxic T lymphocyte antigen 4 gene polymorphism associated with ST-segment elevation acute myocardial infarction. Circ J 2007; 71: 1213-8.

9. Stabej P, Leegwater PA, Imholz S, et al. The canine sarcoglycan delta gene: BAC clone contig assembly, chromosome assignment and interrogation as a candidate gene for dilated cardiomyopathy in Dobermann dogs. Cytogenet Genome Res 2005; 111: 140-6.

10. Dahl CP, Husberg C, Gullestad L, et al. Increased production of CXCL16 in experimental and clinical heart failure: a possible role in extracellular matrix remodeling. Circ Heart Fail 2009; 2: 624 32.

11. Szmit S, Jank M, Maciejewski H, et al. Gene expression profiling in peripheral blood nuclear cells in patients with refractory ischaemic end-stage heart failure. J Appl Genet 2010; 51: 353-68.
12. Velagaleti RS, O’Donnell CJ. Genomics of heart failure. Heart Fail Clin 2010; 6:115-24. (Review)

13. Yancy CW, Lopatin M, Stevenson LW, De Marco T, Fonarow GC. Clinical presentation, management, and in-hospital outcomes of patients admitted with acute decompensated heart failure with preserved systolic function: a report from the Acute Decompensated Heart Failure National Registry (ADHERE) Database. J Am Coll Cardiol 2006; 47: 76-84.

14. Nieminen MS, Brutsaert D, Dickstein K, et al. EuroHeart Failure Survey II (EHFS II): a survey on hospitalized acute heart failure patients: description of population. Eur Heart J 2006; 27: 2725-36.

15. Filippatos G, Zannad G. An introduction to acute heart failure syndromes: definition and classification. Heart Fail Rev 2007; 12: 8790. (Review)

16. Dickstein K, Cohen-Solal A, Filippatos G, et al. ESC Guidelines for the diagnosis and treatment of acute and chronic heart failure 2008: the Task Force for the Diagnosis and Treatment of Acute and Chronic Heart Failure 2008 of the European Society of Cardiology. Developed in collaboration with the Heart Failure Association of the ESC (HFA) and endorsed by the European Society of Intensive Care Medicine (ESICM). Eur Heart J 2008; 29: 2388442. (Review)

17. Fonarow GC, Adams KF Jr, Abraham WT, Yancy CW, Boscardin WJ. Risk stratification for in-hospital mortality in acutely decompensated heart failure: classification and regression tree analysis. JAMA 2005; 293: 572-80.

18. Nieminen MS, Böhm M, Cowie MR, et al. Executive summary of the guidelines on the diagnosis and treatment of acute heart failure: the Task Force on Acute Heart Failure of the European Society of Cardiology. Eur Heart J 2005; 26: 384-416.

19. Goeman JJ, van de Geer SA, de Kort F, van Houwelingen HC. A global test for groups of genes: testing association with a clinical outcome. Bioinformatics 2004; 20: 93-9.

20. Smyth GK. Linear models and empirical Bayes methods for assessing differential expression in microarray experiments. Stat Appl Genet Mol Biol 2004; 3: Article 3.

21. Livak KJ, Schmittgen TD. Analysis of relative gene expression data using real-time quantitative PCR and the $2^{-\Delta \Delta C} \mathrm{~T}$ method. Methods 2001; 25: 402-8.

22. Ronco C, Haapio M, House AA, Anavekar N, Bellomo R. Cardiorenal syndrome. J Am Coll Cardiol 2008; 52: 1527-39. (Review)

23. Tang WH, Mullens W. Cardiorenal syndrome in decompensated heart failure. Heart 2010; 96: 255-60. (Review)

24. Shrestha K, Tang WH. Cardiorenal syndrome: diagnosis, treatment, and clinical outcomes. Curr Heart Fail Rep 2010; 7: 167-74. (Review)

25. Smith GL, Lichtman JH, Bracken, et al. Renal impairment and outcomes in heart failure: systematic review and meta-analysis. $\mathrm{J}$ Am Coll Cardiol 2006; 47: 1987-96. (Review)

26. McClellan WM, Flanders WD, Langston RD, Jurkovitz C, Presley C. Anemia and renal insufficiency are independent risk factors for death among patients with congestive heart failure admitted to community hospitals: a population-based study. J Am Soc Nephrol 2002; 13: 1928-36

27. McAlister FA, Ezekowitz J, Tonelli M, Armstrong PW. Renal insufficiency and heart failure: prognostic and therapeutic implications from a prospective cohort study. Circulation 2004; 109: 1004-9.

28. Smith GL, Shlipak MG, Havranek EP, et al. Race and renal impairment in heart failure: mortality in blacks versus whites. Circulation 2005; 111: 1270-7.

29. Ezekowitz J, McAlister FA, Humphries KH, et al. The association among renal insufficiency, pharmacotherapy, and outcomes in 6,427 patients with heart failure and coronary artery disease. J Am Coll Cardiol 2004; 44: 1587-92.

30. Bowden DW. Genetics of kidney disease. Kidney Int Suppl 2003; 63: S8-12. (Review)

31. Luttropp K, Lindholm B, Carrero JJ, et al. Genetics/Genomics in chronic kidney disease--towards personalized medicine? Semin Dial 2009; 22: 417-22. (Review) 
32. Silvestre JS, Robert V, Heymes C, et al. Myocardial production of aldosterone and corticosterone in the rat. Physiological regulation. J Biol Chem 1998; 273: 4883-91.

33. Takeda Y, Miyamori I, Yoneda T, et al. Production of aldosterone in isolated rat blood vessels. Hypertension 1995; 25: 170-3.

34. Weber KT, Brilla CG. Pathological hypertrophy and cardiac interstitium. Fibrosis and renin-angiotensin-aldosterone system. Circulation 1991; 83: 1849-65. (Review)

35. Monahan KD, Leuenberger UA, Ray CA. Aldosterone impairs baroreflex sensitivity in healthy adults. Am J Physiol Heart Circ Physiol 2007; 292: H190-7.

36. Barr CS, Lang CC, Hanson J, Arnott M, Kennedy N, Struthers AD. Effects of adding spironolactone to an angiotensin-converting enzyme inhibitor in chronic congestive heart failure secondary to coronary artery disease. Am J Cardiol 1995; 76: 1259-65.

37. Tomaschitz A, Pilz S, Ritz E, Meinitzer A, Boehm BO, März W. Plasma aldosterone levels are associated with increased cardiovascular mortality: the Ludwigshafen Risk and Cardiovascular Health (LURIC) study. Eur Heart J 2010; 31: 1237-47.

38. Pitt B, Zannad F, Remme WJ, et al. The effect of spironolactone on morbidity and mortality in patients with severe heart failure. Randomized Aldactone Evaluation Study Investigators. N Engl J Med 1999; 341: 709-17.

39. Pitt B, Remme W, Zannad F, et al. Eplerenone, a selective aldosterone blocker, in patients with left ventricular dysfunction after myocardial infarction. N Engl J Med 2003; 348: 1309-21.

40. Pitt B, Williams G, Remme W, et al. The EPHESUS trial: eplerenone in patients with heart failure due to systolic dysfunction complicating acute myocardial infarction. Eplerenone Post-AMI Heart Failure Efficacy and Survival Study. Cardiovasc Drugs Ther 2001; 15: 79-87.

41. Schwinger RH, Bundgaard H, Müller-Ehmsen J, Kjeldsen K. The Na, K-ATPase in the failing human heart. Cardiovasc Res 2003; 57: 913-20. (Review)

42. Nørgaard A, Bagger JP, Bjerregaard P, Baandrup U, Kjeldsen K, Thomsen PE. Relation of left ventricular function and Na, Kpump concentration in suspected idiopathic dilated cardiomyopathy. Am J Cardiol 1988; 61: 1312-5.

43. Ishino K, Bøtker HE, Clausen T, Hetzer R, Sehested J. Myocardial adenine nucleotides, glycogen, and $\mathrm{Na}$, K-ATPase in patients with idiopathic dilated cardiomyopathy requiring mechanical circulatory support. Am J Cardiol 1999; 83: 396-9.

44. Borlak J, Thum T. Hallmarks of ion channel gene expression in end-stage heart failure. FASEB J 2003; 17: 1592-608.

45. Kihara Y, Grossman W, Morgan JP. Direct measurement of changes in intracellular calcium transients during hypoxia, ischemia, and reperfusion of the intact mammalian heart. Circ Res 1989; 65: 1029-44.

46. Van Emous JG, Vleggeert-Lankamp CL, Nederhoff MG, Ruigrok TJ, Van Echteld CJ. Postischemic Na+-K+- ATPase reactivation is delayed in the absence of glycolytic ATP in isolated rat hearts. Am J Physiol Heart Circ Physiol 2001; 280: H2189-95.

47. Dahlberg J, Nilsson LO, von Wowern F, Melander O. Polymorphism in NEDD4L is associated with increased salt sensitivity, reduced levels of P-renin and increased levels of Nt-proANP. PLoS One 2007; 2: e432.

48. Jin HS, Hong KW, Lim JE, et al. Genetic variations in the sodium balance-regulating genes ENaC, NEDD4L, NDFIP2 and USP2 influence blood pressure and hypertension. Kidney Blood Press Res 2010; 33: 15-23.

49. Svensson-Färbom P, Wahlstrand B, Almgren P, et al. A functional variant of the NEDD4L gene is associated with beneficial treatment response with $\beta$-blockers and diuretics in hypertensive patients. J Hypertens 2011; 29: 388-95.

50. Horwitz PA, Tsai EJ, Putt ME, et al. Detection of cardiac allograft rejection and response to immunosuppressive therapy with peripheral blood gene expression. Circulation 2004; 110: 3815-21.

51. Wingrove JA, Daniels SE, Sehnert AJ, et al. Correlation of peripheral-blood gene expression with the extent of coronary artery stenosis. Circ Cardiovasc Genet 2008; 1: 31-8.

52. Cappuzzello C, Napolitano M, Arcelli D, et al. Gene expression profiles in peripheral blood mononuclear cells of chronic heart failure patients. Physiol Genomics 2009; 38: 233-40.

53. Devaux Y, Azuaje F, Vausort M, Yvorra C, Wagner DR. Integrated protein network and microarray analysis to identify potential biomarkers after myocardial infarction. Funct Integr Genomics 2010; 10: 329-37.

54. Lin D, Hollander Z, Ng RT, et al. Whole blood genomic biomarkers of acute cardiac allograft rejection. J Heart Lung Transplant 2009; 28: 927-35. 